\title{
The Effect of Chair Backrest on Respiratory Function in Prolonged Sitting Position
}

\author{
Chang Ju Kim ${ }^{1}$, Sung Min Son', Kyung Woo Kang ${ }^{2}$ \\ ${ }^{1}$ Department of Physical Therapy, College of Health Science, Cheongju University, Cheongju; ${ }^{2}$ Department of Physical Therapy, Yeungnam University \\ College, Daegu, Korea
}

Purpose: The purpose of this study was to determine the effects of a chair backrest on respiratory function after prolonged sitting. Methods: Twenty-four young healthy subjects (12 males and 12 females) volunteered to participate in this study, and were equally allocated to a backrest $(n=12)$ or a without backrest group $(n=12)$. A spirometer was used to measure the respiratory functions of all subjects.

Results: The chair with backrest group were significant difference in forced vital capacity (FVC), Forced expiratory volume in 1 second (FEV1), and peak expiratory flow (PEF) after sitting for 1 hour, compared with chair without backrest group $(p<0.05)$. The chair with backrest group showed a significantly decreased in FVC, FEV1, and PEF.

Conclusion: Using a chair without a backrest may help to reduce lung function deterioration as compared with a chair with a backrest.

Keywords: Chair backrest, Respiratory function, Prolonged sitting

\section{INTRODUCTION}

Sitting for too long is known to causes various conditions, which are collectively referred to as 'diseases of inactivity.'. Prolonged sitting has been shown to be detrimentally associated with systolic and diastolic blood pressure, type 2 diabetes, total cholesterol, LDL cholesterol, triglycerides, and waist circumference..$^{2-4}$ In addition, prolonged sitting changes body posture, and these in turn affect trunk muscle activity, such as, of the iliocostalis lumborum, multifidus, internal oblique, transverse abdominis muscles. ${ }^{5}$

Abdominal muscles play roles in respiration, ${ }^{67}$ and their activities affect posture, which suggests respiratory function is probably associated with posture. ${ }^{8}$ In a previous study, it was suggested that an upright sitting posture is associated with higher internal oblique, transverse abdominis and iliocostalis lumborum muscle activities as compared with a slumped sitting posture. These findings show abdominal muscles are activated differently by different sitting posi-

Received May 16, 2018 Revised Jun 16, 2018

Accepted Jun 19, 2018

Corresponding author Kyung Woo Kang

E-mail zephyr0001@hanmail.net tions. In other words, sitting posture affects respiratory function, which implies certain sitting positions are better than other in terms of respiration and abdominal muscle activation. ${ }^{8}$

Prolonged sitting is generally defined as sitting continuously more than 30 minutes. When an individual sits on a chair for a long time, his/her posture is determined by the environment, ${ }^{10}$ such as, by the height of the chair or table. ${ }^{11-13}$ Furthermore, changes in posture and in trunk muscle activity may be affected by the presence of a chair backrest. ${ }^{14}$

Many studies have addressed postural changed caused by sedentary behavior or prolonged sitting, but few have examined factors that influence sitting postures or the relation between sitting posture and respiratory function. Therefore, we investigated the effects of a chair backrest on posture and respiratory functions during prolonged sitting. 


\section{METHODS}

\section{Subjects}

Twenty-four young healthy subjects (12 males and 12 females) volunteered to participate in this study, and were equally allocated to either a backrest group $(n=12)$ or a without backrest group $(n=12)$. Each group consisted of six males and six females. Candidates were excluded if they had a cardiovascular disease, an orthopedic spinal problem, could not sit on a stool independently, or could not sit on a stool without lower back pain. Prior to participation, the purpose of this study was explained to all participants and all participants were required to read and sign an informed consent form.

\section{Experimental methods}

\section{1) Measurement}

Subjects were asked to sit on a chair adjusted to their popliteal crease height without armrests and with or without a backrest for 1 hour, a goniometer was used to ensure $90^{\circ}$ angles at hips and knees and ankles. Feet were positioned shoulder width apart, and arms were relaxed. Subjects were instructed to sit as they usually do and watched a movie on a monitor at eye level.

Measurements were conducted using a spirometer (COSMED, SRL, Italy), which is an instrument used to measure pulmonary function, while subjects were in an upright sitting position on the chair. To obtain measurements, subjects blew into a mouthpiece connected to the spirometer. While testing, subjects were informed to look straight ahead and fixate on a nose clip, which prevented air being inhaled or exhaled nasally. Subjects inhaled and exhaled normally three times, and then inhaled and exhaled deeply. To evaluated pulmonary functions, we measured forced vital capacity (FVC), forced expiratory volume in 1 second (FEV1), FEV1/FVC ratio, and peak expiratory flow (PEF). These values are commonly used to evaluate the extents of pulmonary disorders, but can be used to test pulmonary function in normal individuals. Testing was conducted based on the recommendations issued by the American thoracic society. ${ }^{15}$ On each occasion testing was performed three times and subjects were allowed to rest for 1 minute between tests. Pulmonary functions were evaluated before and after sitting on the chair for 1 hour.

\section{2) Statistical analysis}

Statistical analyses were conducting using SPSS version 18.0 for Windows. The independent t-test was used to determine the significances of differences between the 'with backrest' and 'without backrest' groups, in terms of baseline data (age, height, and weight). The Shapiro-Wilk test was used to check normalities of distributions, and two-way repeated-measures analysis of variance was used to assess the impact of backrest use on respiratory functions. Statistical significance was accepted for $\mathrm{p}$-values $<0.05$.

Table 1. The general characteristics of subjects

\begin{tabular}{lccc}
\hline & $\begin{array}{c}\text { Without backrest } \\
(n=12)\end{array}$ & $\begin{array}{c}\text { With backrest } \\
(n=12)\end{array}$ & $p$ \\
\hline Male/Female & $6 / 6$ & $6 / 6$ & \\
Age (year) & $20.58 \pm 0.90$ & $21.25 \pm 1.14$ & 0.126 \\
Height $(\mathrm{kg})$ & $165.90 \pm 8.71$ & $164.83 \pm 8.51$ & 0.765 \\
Weight $(\mathrm{cm})$ & $62.03 \pm 8.80$ & $58.58 \pm 8.82$ & 0.349 \\
\hline
\end{tabular}

Mean \pm SD.

Table 2. Comparison of pulmonary function changes in the with and without backrest of chair groups according to prolonged sitting

\begin{tabular}{|c|c|c|c|c|c|c|}
\hline \multirow{3}{*}{ Parameters } & \multicolumn{2}{|c|}{ Without backrest $(n=12)$} & \multicolumn{2}{|c|}{ With backrest $(n=12)$} & \multirow{2}{*}{$\begin{array}{c}\text { Time } \\
\text { F-value }\end{array}$} & \multirow{2}{*}{$\begin{array}{c}\begin{array}{c}\text { Interaction } \\
(\text { Time } \times \text { Group })\end{array} \\
\text { F-value }\end{array}$} \\
\hline & \multirow{2}{*}{ Pre } & \multirow{2}{*}{ Post } & \multirow{2}{*}{ Pre } & \multirow{2}{*}{ Post } & & \\
\hline & & & & & $\mathrm{p}$-value & p-value \\
\hline \multirow[t]{2}{*}{ FVC } & $3.78 \pm 0.78$ & $3.72 \pm 0.76$ & $3.64 \pm 0.71$ & $3.48 \pm 0.73^{*+}$ & $F=28.60$ & $F=5.71$ \\
\hline & & & & & $p=0.000$ & $p=0.026$ \\
\hline \multirow[t]{2}{*}{ FEV1 } & $3.20 \pm 0.66$ & $3.18 \pm 0.67^{+}$ & $3.15 \pm 0.54$ & $2.98 \pm 0.53^{*+}$ & $F=27.07$ & $F=17.77$ \\
\hline & & & & & $p=0.000$ & $p=0.000$ \\
\hline \multirow[t]{2}{*}{ FEV1/FVC } & $0.85 \pm 0.06$ & $0.86 \pm 0.06$ & $0.87 \pm 0.07$ & $0.86 \pm 0.07$ & $F=0.07$ & $F=3.47$ \\
\hline & & & & & $p=0.788$ & $p=0.076$ \\
\hline \multirow[t]{2}{*}{ PEF } & $6.64 \pm 1.99$ & $6.57 \pm 1.89$ & $6.54 \pm 1.84$ & $6.18 \pm 1.61^{*+}$ & $F=10.95$ & $F=4.85$ \\
\hline & & & & & $p=0.003$ & $p=0.038$ \\
\hline
\end{tabular}

Values are presented as mean \pm standard deviation.

FVC: forced vital capacity, FEV1: forced expiratory volume in 1 second, PEF: peak expiratory flow.

*significant difference between pre- and post-test $(p<0.05)$; ${ }^{\dagger}$ significant difference compared with the control group ( $\left.p<0.05\right)$. 


\section{RESULTS}

Demographic data are summarized in Table 1. No significant intergroup difference was found for sex, age, height, or weight ( $p>0.05)$. Table 2 shows the parameters of pulmonary function at the pre- and post-tests of the two groups, in terms of FVC, FEV1, FEV1/FVC, PEF. Two-way repeated measures analysis of pulmonary functions showed that with backrest group were significant interaction in FVC, FEV1, and PEF after sitting for 1 hour, compared without backrest group $(\mathrm{p}<0.05)$. In addition, two-way repeated measures analysis of variance with factor show significant difference between the two group in FVC, FEV1, and PEF. The with backrest group showed a significantly decreased in FVC, FEV1, and PEF. However, there were no significant difference between intra- and inter-group in FEV1/FVC ration.

\section{DISCUSSION}

The purpose of this study was to investigate changes in respiratory function after adopting a sitting posture for a prolonged period of time, and to investigate whether these changes are influenced by the use of a backrest. As a result, the participants showed that their respiratory function tended to decrease overall, with or without the backrest, which was thought to be due to the prolonged sitting posture. Also the results showed that the decrement of respiratory function in a chair with backrest group was significantly greater than in a chair without backrest group.Traditionally FVC, FEV1, FEV1/FVC, and PEF values are used to evaluate for obstructive lung disease, ${ }^{16,17}$ Also, these are used to assess the pulmonary function of normal subjects ${ }^{18}$ and the respiratory functions of children with an abnormal posture, such as, idiopathic scoliosis..$^{19}$ Based on the above facts, we utilized those indicator for evaluating respiratory function on different chair status. As a result, regardless of backrest, the most of the participants showed a tendency that FVC, FEV1, and PEF values were decreased. It may be due to the effect of prolonged sitting. There have been some studies that the prolonged sitting could affect lung function adversely. 20,21

The results of our study showed that the lung function of the group using the backrest was decreased than that of the unused group. Generally, the use of the backrest is required to achieve comfort on a seat. ${ }^{22}$ Using a backrest can cause changes in the posture of pelvic and lumbar spine due to the back contacting the backrest. ${ }^{23}$ The curvature of spinal column is closely related with diaphragm function. Thus, changed posture due to the use of the backrest can lead to a decrease diaphragm function and influences lung function. ${ }^{24}$ In addition, the kyphotic curve of thoracic vertebra caused by sitting with a backrest can also decrease of the mobilization of the ribs. ${ }^{25}$ These facts support the reason that the lung function of a group using the backrest is decreased.

In conclusion, our findings have shown that using a chair without backrest in modern sedentary life styles may help to lessen lung function deterioration rather than using a chair with backrest. Our study has the limitations in that the subjects are limited to healthy individuals, and the sample size is small. However, future studies suggest that if the mechanism of posture changing according to the prolonged sitting can be understood and appropriately modified, it is expected that the decrease of the respiratory function which can be reduced due to the sitting posture can be prevented to some extent.

\section{REFERENCES}

1. Owen N, Salmon J, Koohsari MJ et al. Sedentary behaviour and health: mapping environmental and social contexts to underpin chronic disease prevention. Br J Sports Med. 2014;48(3):174-7.

2. Larsen RN, Kingwell BA, Sethi P et al. Breaking up prolonged sitting reduces resting blood pressure in overweight/obese adults. Nutr Metab Cardiovasc Dis. 2014;24(9):976-82.

3. Peddie MC, Bone JL, Rehrer NJ et al. Breaking prolonged sitting reduces postprandial glycemia in healthy, normal-weight adults: a randomized crossover trial. Am J Clin Nutr. 2013;98(2):358-66.

4. Frydenlund G, Jørgensen T, Toft U et al. Sedentary leisure time behavior, snacking habits and cardiovascular biomarkers: the inter99 study. Eur J Prev Cardiol. 2012;19(5):1111-9.

5. Waongenngarm P, Rajaratnam BS, Janwantanakul P. Perceived body discomfort and trunk muscle activity in three prolonged sitting postures. J Phys Ther Sci. 2015;27(7):2183-7.

6. Essendrop M, Schibye B, Hye-Knudsen C. Intra-abdominal pressure increases during exhausting back extension in humans. Eur J Appl Physiol. 2002;87(2):167-73.

7. Hodges PW, Gandevia SC. Changes in intra-abdominal pressure during postural and respiratory activation of the human diaphragm. J Appl Physiol (1985). 2000;89(3):967-76.

8. Kera T, Maruyama $\mathrm{H}$. The effect of posture on respiratory activity of the abdominal muscles. J Physiol Anthropol Appl Human Sci. 2005;24(4): 259-65.

9. O'Sullivan PB, Dankaerts W, Burnett AF et al. Effect of different upright sitting postures on spinal-pelvic curvature and trunk muscle activation in a pain-free population. Spine. 2006;31(19):E707-12.

10. Neuhaus M, Healy GN, Dunstan DW et al. Workplace sitting and 
height-adjustable workstations: a randomized controlled trial. Am J Prev Med. 2014;46(1):30-40.

11. Rodosky MW, Andriacchi TP, Andersson GB. The influence of chair height on lower limb mechanics during rising. J Orthop Res. 1989;7(2): 266-71.

12. Kawagoe S, Tajima N, Chosa E. Biomechanical analysis of effects of foot placement with varying chair height on the motion of standing up. J Orthop Sci. 2000;5(2):124-33.

13. Hassaïne M, Hamaoui A, Zanone PG. Effect of table top slope and height on body posture and muscular activity pattern. Ann Phys Rehabil Med. 2015;58(2):86-91.

14. Curran M, O'Sullivan L, O'Sullivan P et al. Does using a chair backrest or reducing seated hip flexion influence trunk muscle activity and discomfort? a systematic review. Hum Factors. 2015;57(7):1115-48.

15. Miller MR, Hankinson J, Brusasco V et al. Standardisation of spirometry. Eur Respir J. 2005;26(2):319-38.

16. Swanney MP, Ruppel G, Enright PL et al. Using the lower limit of normal for the FEV1/FVC ratio reduces the misclassification of airway obstruction. Thorax. 2008;63(12):1046-51.

17. O’Donnell DE, Lam M, Webb KA. Spirometric correlates of improvement in exercise performance after anticholinergic therapy in chronic obstructive pulmonary disease. Am J Respir Crit Care Med. 1999;
160(2):542-9.

18. Dawson A. Reproducibility of spirometric measurements in normal subjects. Am Rev Respir Dis. 1966;93(2):264-8.

19. McPhail GL, Ehsan Z, Howells SA et al. Obstructive lung disease in children with idiopathic scoliosis. J Pediatr. 2015;166(4):1018-21.

20. Lin F, Parthasarathy S, Taylor SJ et al. Effect of different sitting postures on lung capacity, expiratory flow, and lumbar lordosis. Arch Phys Med Rehabil. 2006;87(4):504-9.

21. Kang KW, Son SM, Ko YM. Time-varying changes in pulmonary function with exposure to prolonged sitting. Osong Public Health Res Perspect. 2016;7(6):382-4.

22. Ng D, Cassar T, Gross CM. Evaluation of an intelligent seat system. Appl Ergon. 1995;26(2):109-16.

23. Vergara M, Page A. System to measure the use of the backrest in sittingposture office tasks. Appl Ergon. 2000;31(3):247-54.

24. Yi LC, Jardim JR, Inoue DP et al. The relationship between excursion of the diaphragm and curvatures of the spinal column in mouth breathing children. J Pediatr (Rio J). 2008;84(2):171-7.

25. Culham EG, Jimenez HA, King CE. Thoracic kyphosis, rib mobility, and lung volumes in normal women and women with osteoporosis. Spine. 1994;19(11):1250-5. 